Delft University of Technology

\title{
Corrosion Sensitivity of LED Packages
}

Jacobs, B.J.C.; van der Marel, C.; van Driel, W.D.; Lu, S.J.; Li, X.P.

DOI

10.1007/978-3-319-58175-0_19

Publication date

2018

Document Version

Final published version

Published in

Solid State Lighting Reliability Part 2

\section{Citation (APA)}

Jacobs, B. J. C., van der Marel, C., van Driel, W. D. (Ed.), Lu, S. J., \& Li, X. P. (2018). Corrosion Sensitivity of LED Packages. In W. D. van Driel, X. Fan, \& G. Q. Zhang (Eds.), Solid State Lighting Reliability Part 2: Components to Systems (1 ed., pp. 527-547). (Solid State Lighting Technology and Application Series; Vol. 3). Springer. https://doi.org/10.1007/978-3-319-58175-0_19

\section{Important note}

To cite this publication, please use the final published version (if applicable).

Please check the document version above.

\section{Copyright}

Other than for strictly personal use, it is not permitted to download, forward or distribute the text or part of it, without the consent of the author(s) and/or copyright holder(s), unless the work is under an open content license such as Creative Commons.

Takedown policy

Please contact us and provide details if you believe this document breaches copyrights.

We will remove access to the work immediately and investigate your claim. 
Green Open Access added to TU Delft Institutional Repository

'You share, we take care!' - Taverne project

https://www.openaccess.nl/en/you-share-we-take-care

Otherwise as indicated in the copyright section: the publisher is the copyright holder of this work and the author uses the Dutch legislation to make this work public. 


\title{
Chapter 19 \\ Corrosion Sensitivity of LED Packages
}

\author{
B.J.C. Jacobs, C. van der Marel, Willem Dirk van Driel, S.J. Lu, and X.P. Li
}

\begin{abstract}
The penetration of solid state lighting applications is due to the promise of a low-cost reliable solution by means of application of low- and mid-power LEDs. These LED packages are manufactured by making use of new processes and materials which in principle introduces a series of known and unknown failure modes. Corrosion is a specific failure mode which limits the lifetime, and hence manufacturers realize that their package integrity needs to be improved. This chapter describes the sensitivity to corrosion of LED packages. In the first part, an introduction to chemical incompatibility is given. In the second part, different sources of corrosion are distinguished. The construction of LED packages and their vulnerability to corrosion is described in the third part. In the fourth part of this chapter, testing methods are reviewed and their effectiveness to simulate real-life conditions. A series of experimental setups is used to explore the behavior of LED packages in contaminated environments. A combined experimental-theoretical approach is used to describe the performance in certain conditions of pollution. This will be covered in the fifth part. The last part describes a list of classes of chemicals, often found in electronics and construction materials for luminaires that may affect LED performance and for this reason should be avoided for the design of SSL solutions.
\end{abstract}

B.J.C. Jacobs $(\bowtie) \cdot$ C. van der Marel

Philips Lighting, High Tech Campus, Eindhoven, The Netherlands

e-mail: boudewijn.jacobs@philips.com; cees.van.der.marel@philips.com

W.D. van Driel $(\bowtie)$

Philips Lighting, High Tech Campus, Eindhoven, The Netherlands

Delft University of Technology, EEMCS Faculty, Delft, The Netherlands

e-mail: willem.van.driel@philips.com

S.J. Lu • X.P. Li

Philips Lighting, Innovation Campus, Shanghai, China

e-mail: alan.sj.lu@philips.com; xiupeng.li@philips.com 


\subsection{Introduction}

SSL applications are now at the doorstep of massive market entry into our offices and homes. This penetration is mainly due to the promise of an increased reliability with an energy-saving opportunity: a low-cost reliable solution by means of application of low- and mid-power LEDs. These LED packages are manufactured making use of new processes and materials which will introduce a series of known and unknown failure modes [1-3]. Semiconductor failure modes are well described [4], but their relation to the quality and reliability of light is not well known. Corrosion of LED packages is a specific failure mode which presently limits their lifetime. While most failure modes of high-power LED packages are being understood [5, 6], these packages are quite robust against corrosion. However, LED package manufacturers realize that the package integrity of low- and mid-power LEDs needs to be improved to achieve comparable lifetimes. LED package performance strongly relies on its lumen depreciation in which the light source gradually but slowly degrades over time [7]. Besides lumen depreciation LED packages may degrade by a shift in color [8-10]. The presence of sulfur- and halogen-containing chemical compounds as well as chemically incompatible volatile organic compounds (VOCs) in LED-based solid state lighting designs may impair the performance and strongly reduce its lifetime. Even if measures are taken to avoid harmful substances in the proximity of electronic components, in general customers still experience corrosion issues. Gradually, manufacturers are gathering field experiences with this new failure mode and developing more robust LED packages. They acknowledge that the robustness against corrosion of low- and mid-power LED package needs to be improved to reach lifetimes similar to high-power LED packages.

Epoxy-based adhesives, elastomers, coatings, and potting compounds are examples of materials frequently used in the construction of luminaires. These products may also face degradation influencing the system lifetime [11, 12]. Additionally they often contain incompatible chemicals leading to a rapid decrease in luminous flux and noticeable shift in chromaticity on LED package level. In extreme cases the chemicals may even lead to a short or open electrical contact. In addition to chemical contamination due to outgassing, consideration must also be given to the environment in which the LED-based lighting solution will be installed and operated. While some degradation mechanisms of mid-power LED packages are described [13, 14], this chapter focusses on the influence of aggressive environments such as corrosive atmospheres, coastal climates, and chemical industry which negatively affect lowand mid-power LED light source behavior and service life.

\subsection{Sources of Corrosion}

Since LEDs are part of a system, they can be exposed to different environmental conditions. Presence of sulfur, halogens, and VOCs in the air may affect the reliability of LED components of the system. We may distinguish different sources of corrosion, as illustrated in the figure below (Fig. 19.1). 


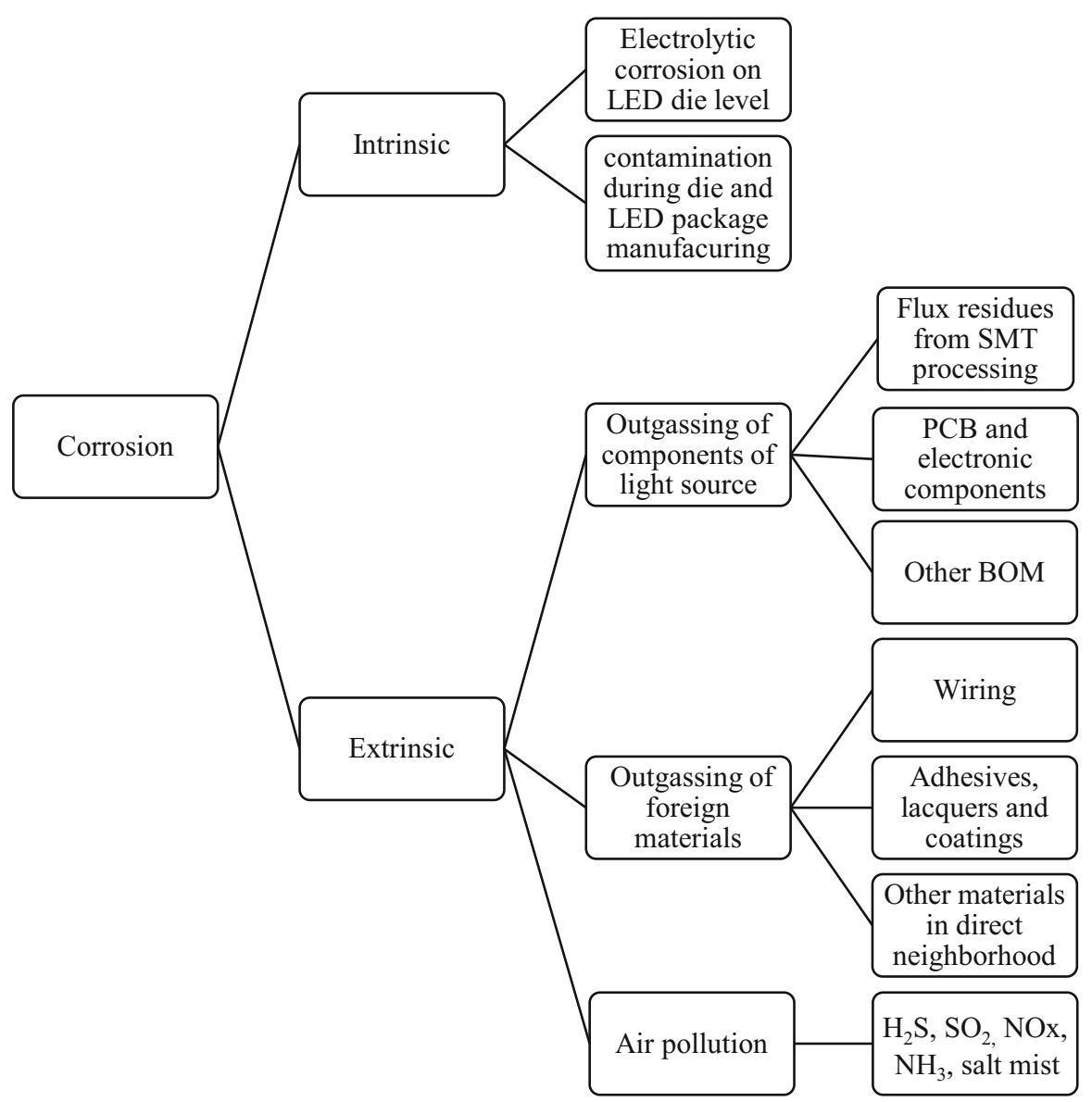

Fig. 19.1 Overview of different sources for LED corrosion

\subsubsection{Intrinsic Corrosion}

Intrinsic corrosion effects are found on different levels inside a LED package. Due to the permeability of the silicone resin for moisture, oxidizing substances, and corrosive gasses, the conducting ITO layer on LED die level may dissolve by electrolytic corrosion. As a consequence, metallic indium is separated and migrates through the LED mesa edge passivation layer leading to electrical shortage of LED p-n junction. One could question if this corrosion mechanism should be classified as an intrinsic or an extrinsic corrosion effect. For some LED packages however, the thickness of the passivation layer seems to be too thin to provide sufficient level of mesa surface protection which makes the surface of the LED mesa edge initially vulnerable to organic acids from the environment and causes local surface leakage channels with ongoing electrolytic reaction. For these specific LEDs, this failure 


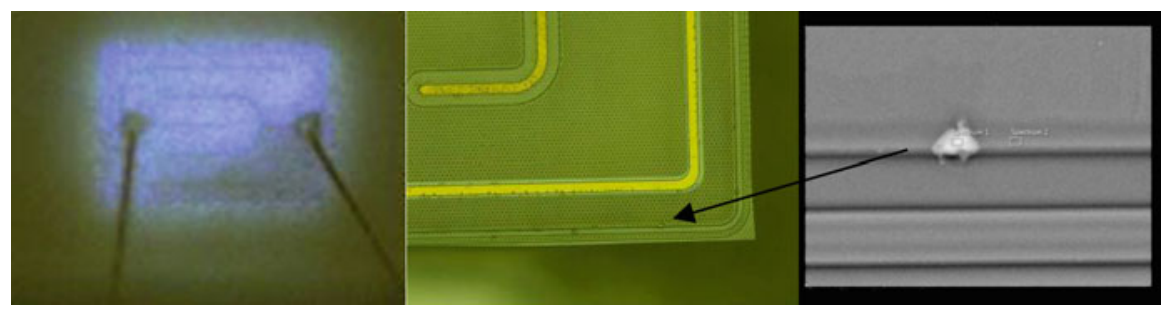

Fig. 19.2 Example of a de-capped MP LED package showing migration of metallic particles at mesa edges

mechanism is observed during exposure to normal humid environmental conditions and could for this reason be classified as intrinsic corrosion. As a result of long continuous surface leakage current flow, chemical reduction of ITO, and agglomeration of indium metallic residuals at the mesa edges, a low-ohmic leakage channel is created which causes a high leakage current. Hence LEDs fail to light up at a certain state of dimming during normal life. In Fig. 19.2, a mid-power (MP) LED package is shown with a leaky chip. During driving a clear dark corner on the bottom right of the chip can be observed. On the exact location, a bright dot at the mesa edge is found. The defects could easily be found with SEM. In almost all cases, the defects mainly consist of indium.

Another example of intrinsic corrosion is found to be caused by chemical residues on the lead frame due to the manufacturing process, either by transport and handling of the lead frames before silicone dispense or by the use of materials, tools, equipment, or process consumables containing typical chlorine or sulfur. Although chlorine may be present on the lead frame as contaminant during manufacturing, causing silver tarnish, it may not be able to detect presence of chlorine after a period of operation since chlorine gradually leaves the LED package as gaseous hydrogen chloride by diffusion. In the figure below, the lumen maintenance of a MP LED package is shown during a steady-state wet high-temperature operation test. Initially, chlorine was present at the surface of the Ag-mirror; the amount of chlorine can be expressed by the ratio of the surface concentrations of chlorine $(\mathrm{Cl})$ over silver $(\mathrm{Ag})$ (surface concentrations are concentrations in the upper few $\mathrm{nm}$ ). In this case the initial concentration ratio $\mathrm{Cl} / \mathrm{Ag}$ was larger than $10 \%$. The figure shows that the products suffering from intrinsic corrosion do not follow a time-single-exponential lumen decay (dashed line) but tend to depreciate significantly faster after some time (solid line) (Fig. 19.3).

Also contaminated materials inside the LED, such as phosphors, silicone, or adhesives, could cause intrinsic corrosion. And PCB material, in particular CEM type, generally contains some small amounts of bromide. If, for instance, by diffusion, bromide reaches the silver-coated lead frame, it will lead to the formation of silver bromide, decreasing the reflectivity of the internal reflector and hence reducing the LED package lifetime. 


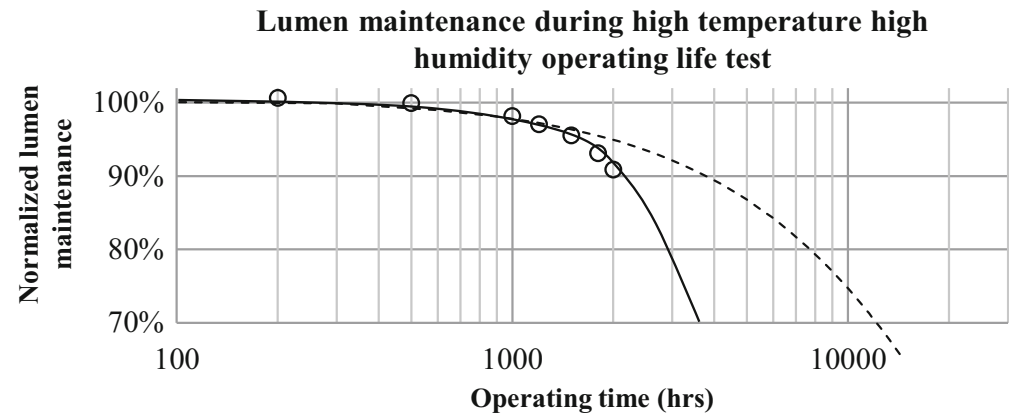

Fig. 19.3 Normalized lumen maintenance during high temperature and high humidity operating life test. The dashed line represents normal lumen maintenance behavior, while the dots and solid trend line represent behavior of MP LED packaging showing early wear-out by intrinsic chlorine corrosion

Even at room temperature, remnants of flux desorb significantly organic components like nitrogen-containing fatty acids. By consequence, a leaking path between flux remnants and the silver mirror in LED modules must be avoided.

\subsubsection{Extrinsic Corrosion}

Extrinsic corrosion can be split up by:

- Outgassing of components that are used in the product itself

- Outgassing of materials used in the direct environment of the lamp or luminaire

- Climatic air pollution

In general application guides from manufacturers of LED packages and LED-based lighting solutions describe the effect of extrinsic corrosion and give guidance to protect the product from this failure mode [15].

\subsubsection{Corrosion by Components of Light Source}

Due to the proximity of various components and materials in a system, the environmental chemical conditions of LEDs are often originating from the system itself. Especially at higher temperatures, aggressive substances like $\mathrm{H}_{2} \mathrm{~S}$, halogens, as well as volatile organic compounds (VOCs) evaporating from materials like foam pads, rubber sealing, anti-vibration pads, or thermal conductive pads will affect the degradation of luminous flux in LEDs. Below results from gas chromatography mass spectroscopy measurements are shown during baking of a commercial available electronic transformer component. As can be seen from the figure, the release of bromide-, chlorine-, and sulfur-containing compounds is minimized to approximately zero, indicating that harmful corrosion effects could by minimized by baking this component for a certain time period (Fig. 19.4). 


\section{Relative release of bromide, chlorine and sulfur as function of bake-out time}

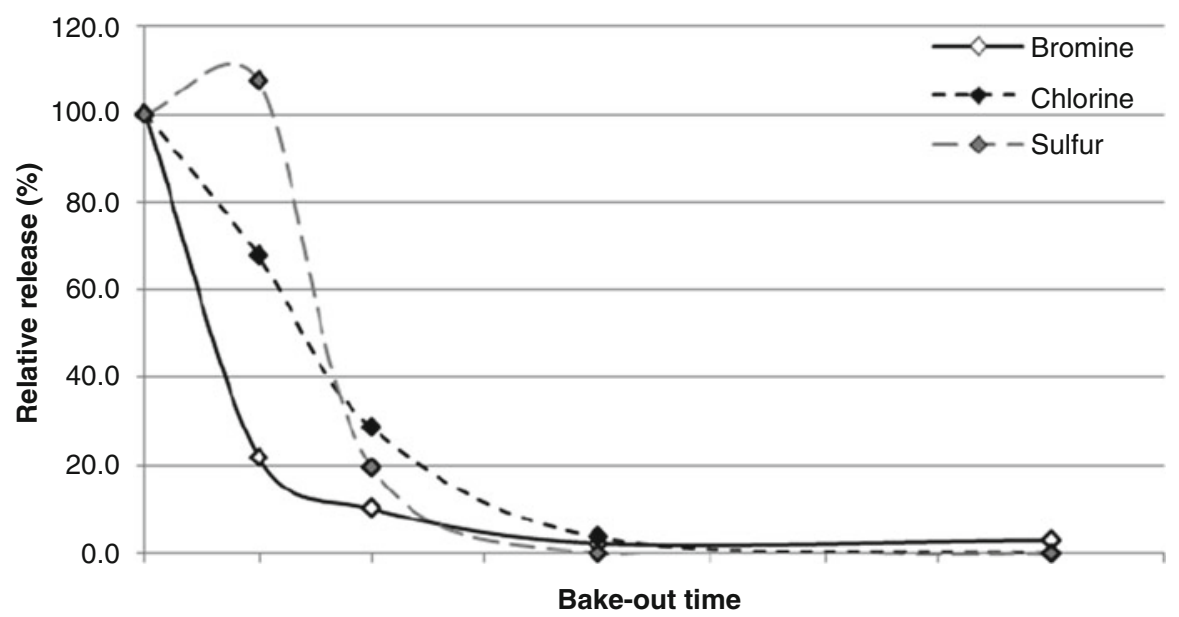

Fig. 19.4 The release of bromine, chlorine, and sulfur as function of bake-out time of an electronic transformer; the release is negligible after some time

\subsubsection{Corrosion by Outgassing of Materials from the Environment}

Local environmental contamination can be caused by materials that are used in the close neighborhood of the lighting system. Ceiling panels treated with a fungicide often contain iodine which negatively affects the reliability of LED packages in the system. LED manufacturers generally maintain a list of chemicals in their application guides and product description sheets that are often found in electronics and construction materials for luminaires that should be avoided. In $\S 19.6$ more information on harmful chemicals can be read.

\subsubsection{Corrosion by Air Pollution}

Air pollutants as sulfur dioxide $\left(\mathrm{SO}_{2}\right)$, nitrogen dioxide $\left(\mathrm{NO}_{2}\right)$, hydrogen sulfide $\left(\mathrm{H}_{2} \mathrm{~S}\right)$, chlorine $\left(\mathrm{Cl}_{2}\right)$, and ammonia $\left(\mathrm{NH}_{3}\right)$ which are present in air promote corrosion of metals and need to be taken into consideration in the evaluation of corrosion resistance of products that are especially sensitive to corrosion failures such as electronic devices. Exposure tests in the presence of such air pollutants are therefore frequently used in the qualification of electronic products to determine the corrosion resistance. 
Corrosion by air pollution is critical in case light sources are used in areas with moderate or high activities of industry or traffic. Air pollution is mainly caused by industry, traffic, power stations, heating systems, and waste disposal facilities. Moisture-rich environments are extra vulnerable.

\subsection{Sensitivity to Corrosion by LED Package Design}

In the interest of both protecting the LED chip and maximizing the light that is coupled out, all LED packages feature some form of encapsulation. Silicones are frequently used for transparent encapsulation. The silicone is added with phosphor as light converter material.

Silicones possess a high optical transparency, favorable mechanical properties, and thermal and radiation stability but are to some extent permeable for gases. Some VOCs and chemicals react with silicone and produce discoloration and surface damage. Other VOCs do not chemically react with the silicone material directly but diffuse into the silicone and oxidize during the presence of heat or light. Since silicone permeability increases with temperature, more VOCs may diffuse into and/or evaporate out from the silicone at elevated temperatures [15].

A typical high-power (HP) LED package contains a high brightness LED chip on a ceramic substrate. The ceramic substrate provides mechanical support and thermally connects the LED chip to a heat pad on the bottom of the substrate. An electrical interconnect layer connects the LED chip to a cathode and anode on the bottom of the substrate. In contrast to HP LED packages, low-power (LP) and mid-power LED packages consist of a silver-coated lead frame with polycyclohexylenedimethylene terephthalates (PCT), polyphthalamide (PPA), or epoxy molding compound (EMC)-based housing. Here, a LED die is glued to the lead frame and electrically connected to the lead frame with bond wires. The LED is casted with a silicone-based encapsulation to protect the die and wire bond. Refer to Fig. 19.5 .

\subsubsection{Package Integrity}

In general, the sensitivity for corrosion of a LED package depends mainly upon the package integrity of the LED package. The figure below shows a cross section of a MP LED package (Fig. 19.6).

Possible passages of sulfur, halogens, and VOCs to reach the silver-coated lead frame are:

- Through the silicone (A)

- Interface mold compound and silicone (B)

- Interface mold compound and metal lead frame interface (C) 


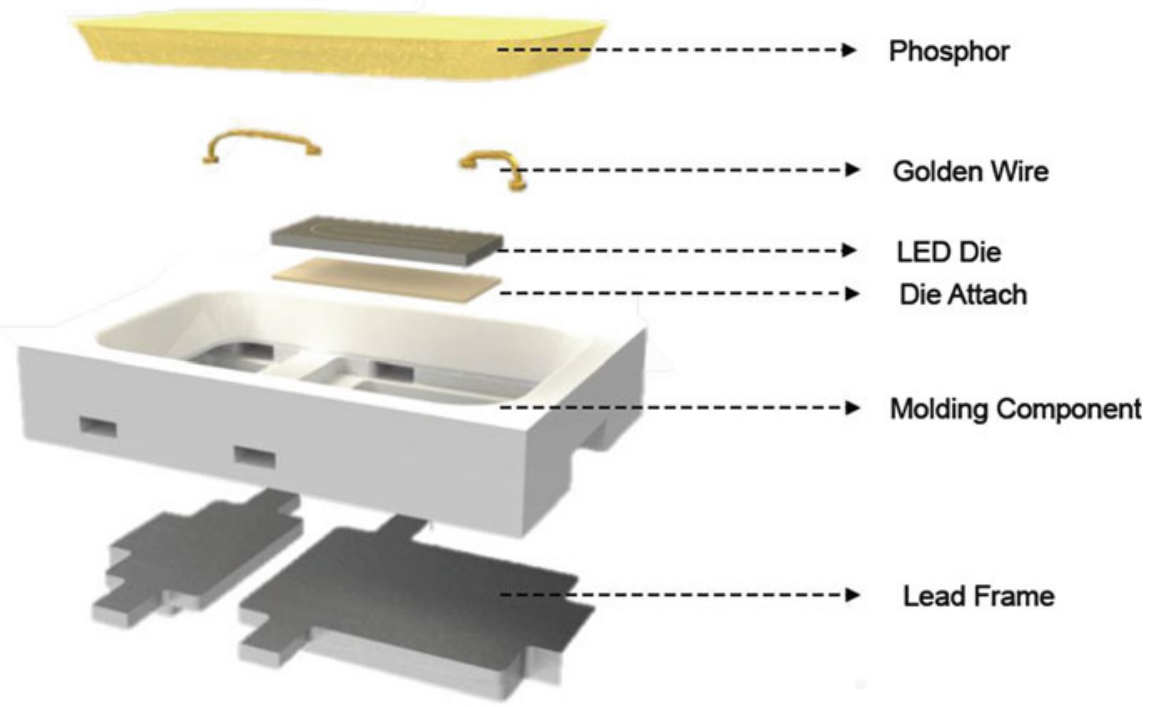

Fig. 19.5 Typical construction of a low- and mid-power LED package

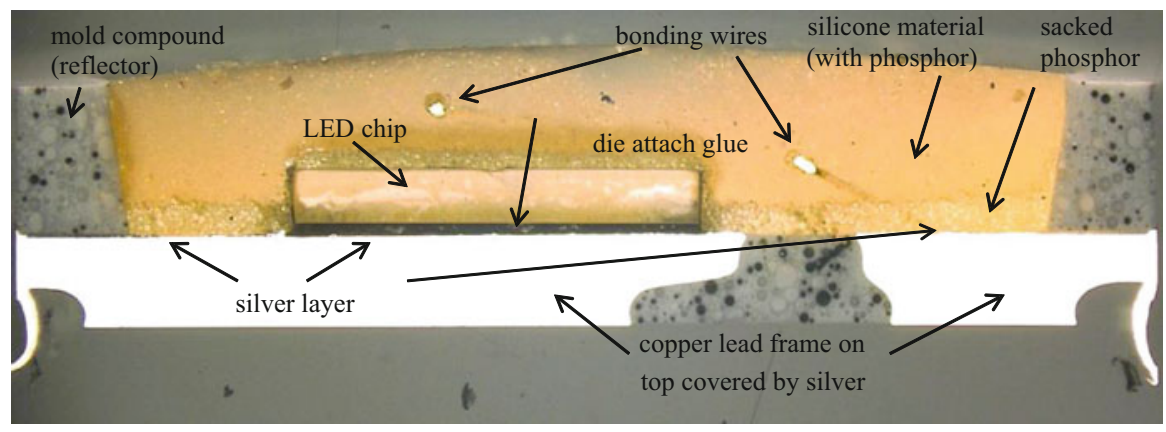

Fig. 19.6 Cross section of a typical mid-power LED package

An example of a passage along the mold compound and silicone (B) can be seen on the picture below. Clearly a gap is visible enabling corrosive gasses to penetrate into the package and attacking the silver layer very easily (Fig. 19.7).

Besides ingress of sulfur and halogens at locations of interlayer delamination and through the silicone, also diffusion of VOCs at the same locations should be considered. 


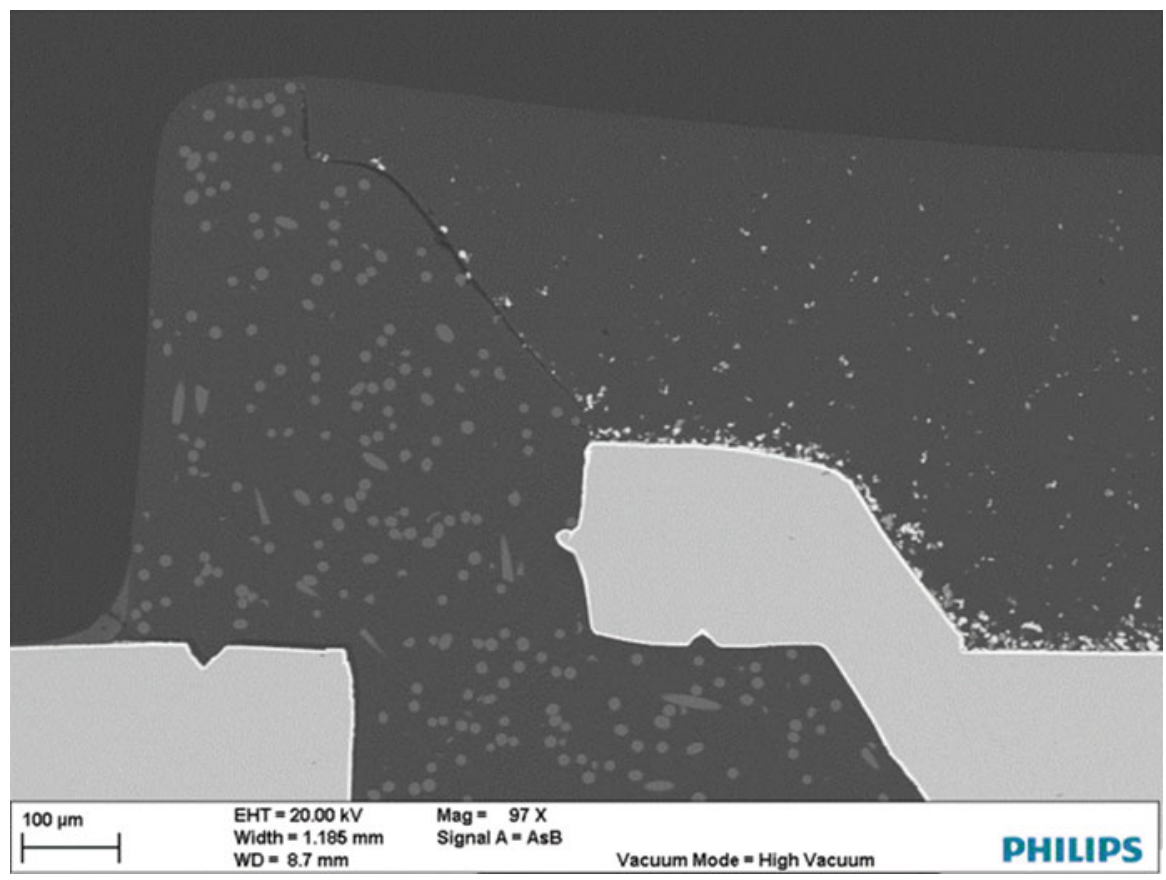

Fig. 19.7 Electron micrograph of a MP LED package cross section showing a clear passage to the lead frame by delamination along the mold compound and silicone

\subsubsection{Corrosion-Sensitive Materials}

Silver, being an excellent reflecting material, is used as a reflector on top of the lead frame to increase the amount of emitting light from the package. Silver is known to corrode quite easily, a phenomenon that is called tarnish. It is known that sulfur and halogens act as a catalyzer for this corrosion. Tarnish is the result of an oxidation reaction between a metal and some chemical in its environment. Unlike rust, which continues to eat away the underlying metal even after it has covered the metal's surface, tarnish continues to grow at a slower rate as soon as one mono-atomic layer has been formed. It forms a gray-black-colored patina, a layer of already-oxidized metal compound, known as silver sulfide $\left(\mathrm{Ag}_{2} \mathrm{~S}\right)$ that protects the remaining metal below it by excluding the oxidizing agent, preventing it from making further contact with the fresh metal. It forms when elemental silver (Ag) is exposed to hydrogen sulfide $\left(\mathrm{H}_{2} \mathrm{~S}\right)$, the gas responsible for the familiar "rotten egg smell" of organic sulfur compounds. When the two chemicals meet and also oxygen is present, they react. The sulfur breaks away from its two hydrogens to form two new covalent bonds with silver atoms. This makes silver sulfide $\left(\mathrm{Ag}_{2} \mathrm{~S}\right)$ and releases water $\left(\mathrm{H}_{2} \mathrm{O}\right)$. Silver tarnish is caused by sulfur compounds, but oxygen or other oxidant compounds are necessary for the reaction to happen. The balanced equation is written below: 


$$
4 \mathrm{Ag}+2 \mathrm{H}_{2} \mathrm{~S}+\mathrm{O}_{2} \leftrightarrow 2 \mathrm{Ag}_{2} \mathrm{~S}+2 \mathrm{H}_{2} \mathrm{O}
$$

Silver can also be tarnished by exposure to chlorine $\left(\mathrm{Cl}_{2}\right)$. Other potentially harmful photosensitive compounds are iodine $\left(\mathrm{I}_{2}\right.$ or organic $\left.\mathrm{I}->\mathrm{AgI}\right)$, bromide $\left(\mathrm{Br}_{2}\right.$ or organic $\left.\mathrm{Br}->\mathrm{AgBr}\right)$, as well as organic acids $(\mathrm{R}-\mathrm{C}=\mathrm{O}-\mathrm{OH}->\mathrm{R}-\mathrm{C}=\mathrm{O}-$ $\mathrm{O}-\mathrm{Ag})$.

These silver compounds all give rise - even without irradiation with light - to a cyclic reaction and corrosion of the silver-plated lead frame.

Below a picture is shown of a series of MP LED packages which suffered severe silver tarnish by $\mathrm{H}_{2} \mathrm{~S}$. The high permeability of the silicone encapsulation allows $\mathrm{H}_{2} \mathrm{~S}$ gas to diffuse to the silver, even in a nonoperational state. The leakage of the lead frame is in this case not the primary cause of Ag-tarnish since for this particular LED package, $\mathrm{H}_{2} \mathrm{~S}$ reaches the silver surface much faster through the silicone than through the lead frame. The mechanically de-capped LED packages on the right clearly show that silver particles are migrated into the silicone (Fig. 19.8).

Corrosion of the silver plating of the lead frame may finally result in the destruction of the electrical contact between lead frame and the die by a lifting ball or wedge bond. Below a SEM picture of a wedge bond is shown of samples suffering from corrosion. On the wire clear traces of silver migration are visible (Fig. 19.9)

Manufacturers are constantly developing less sensitive LED packages by applying protective layers and less permeable silicones or are changing over to highreflective mold compounds or application of gold finish instead of silver. As an example, the graph below shows the normalized lumen maintenance of a LED package containing a silver (solid line)- and gold (dashed line)-plated lead frame, respectively, during a binary gas exposure test showing a large improvement in lumen maintenance for the latter product (Fig. 19.10).

\subsubsection{Hitting Probability on Surface}

Lumen decay by corrosion of a LED package depends mainly upon the package integrity, the use of corrosive sensitive metals in the LED package, and their contribution to the reflectiveness of these metals to the total light output.

By determining the hitting probability on surface (HPOS) of the lead frame, one can determine its sensitivity for corrosion by design. The HPOS value represents the average probability that an emitted photon from the chip (epi-die) hits a particular surface area before it leaves the package. In Fig. 19.11 the left columns show the HPOS on the side wall reflector (plastic PPA/PCT/EMC), while the right columns give information about the HPOS on the silver-coated lead frame. Please note that the mentioned HPOS value is not valid for each commercially available 


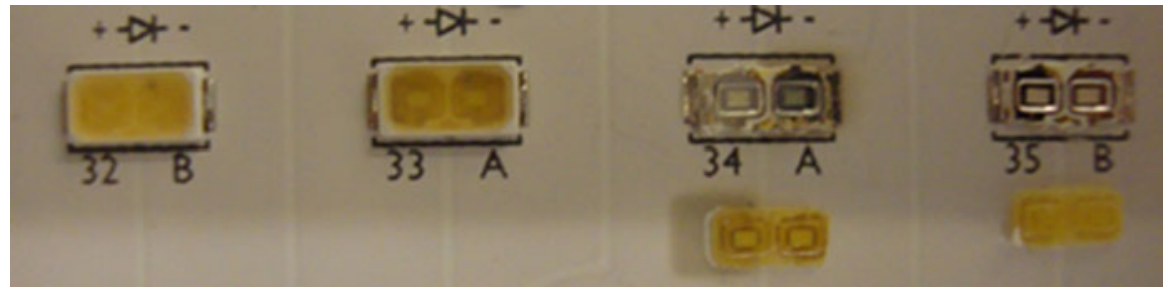

Fig. 19.8 Picture of MP LED packages with silver tarnish in which silver particles are migrated into the silicone

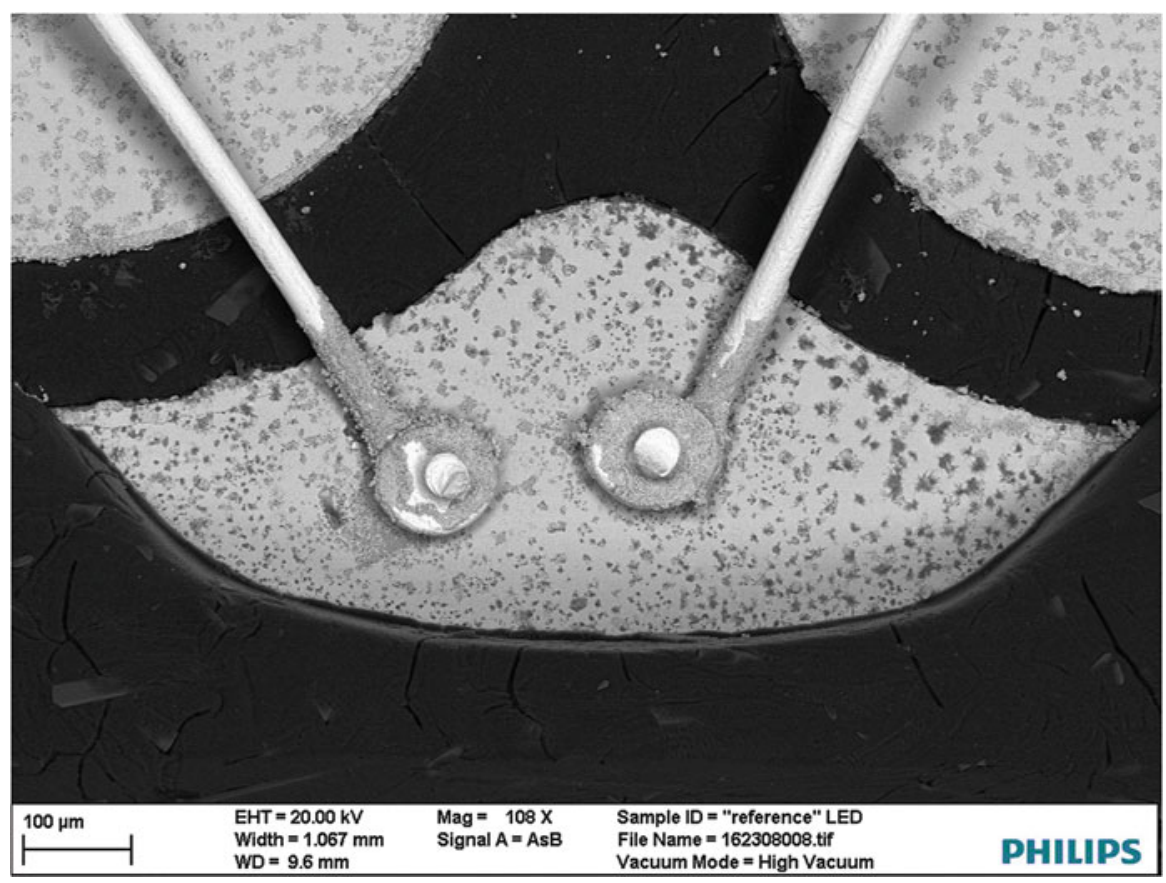

Fig. 19.9 Picture of a MP LED package showing silver migration effect on the wire bonds. The part of the gold wires close to the wire bond is covered with silver (dark gray)

LED package for the mentioned typical package sizes since the LED package design for a specific package size may differ per LED manufacturer.

From the figure above, one can conclude that, by design, the probability that the emitted light from the die for a specific 5630-package will hit the reflector is only very limited compared to the probability that the emitted light will hit the silver surface. This package is therefore very sensitive for the decrease in reflectivity of the silver layer but is less sensitive for the decrease in reflectivity of the plastic reflector. When comparing this package to 3014-size packages, one may conclude that this latter package suffers severe influence of photons hitting the reflector. 


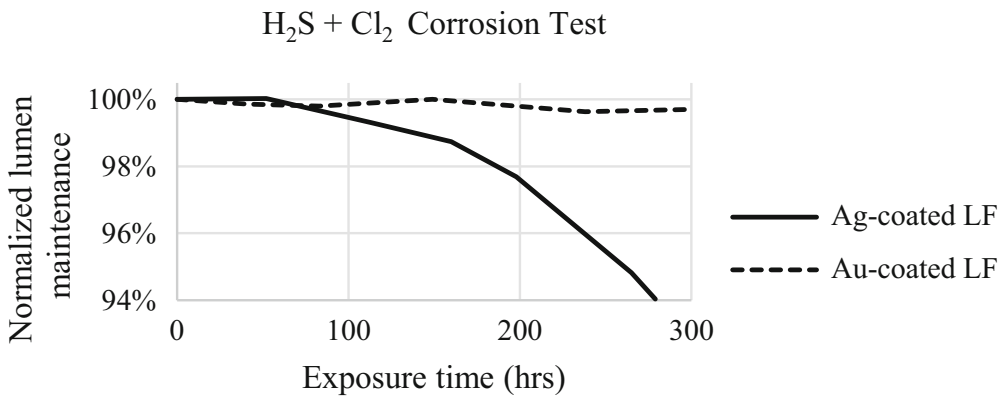

Fig. 19.10 Normalized lumen maintenance of a MP LED package with silver- (solid line) and gold (dashed line)-plated lead frame during a binary corrosion test

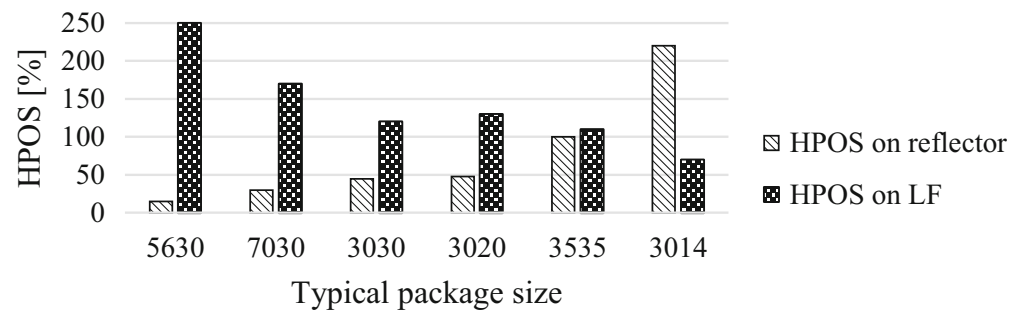

Fig. 19.11 Hitting probability on surface of the side reflector and lead frame of some typical MP LED package sizes

During qualification tests, it was observed that the dominant failure mode of this 3014-size package was indeed discoloring of the plastic material causing lumen decay and color change, while at the 5630-package, the observed lumen decay and color change was mainly caused by change of the reflectivity of the silver mirror.

\subsection{Corrosion Test Methods}

\subsubsection{Standard Test Methods}

Corrosion tests have been developed in the 1980s by researchers at Battelle Labs, Telcordia, and IBM by using gas tests to accelerate atmospheric corrosion and its effect on electronic applications [16]. A gas test is a laboratory test in which the temperature, relative humidity, concentration of gaseous pollutants, and other critical variables such as volume exchange rate and airflow rate are carefully defined, monitored, and controlled. The purpose of this test is to simulate corrosion phenomena due to atmospheric exposure. In early 1990s, professional organizations, including American Society for Testing and Material (ASTM), Electronic Industries Association (EIA), International Electro technical Commission (IEC), 
Table 19.1 Mixed flowing gas test methods developed by IEC 60068-2-60 Part 2 [16]

\begin{tabular}{l|l|l|l|l}
\hline Parameter & Method 1 & Method 2 & Method 3 & Method 4 \\
\hline $\mathrm{H}_{2} \mathrm{~S}\left(10^{-9} \mathrm{vol} / \mathrm{vol}\right)$ & $100 \pm 20$ & $10 \pm 5$ & $100 \pm 20$ & $10 \pm 5$ \\
\hline $\mathrm{NO}_{2}\left(10^{-9} \mathrm{vol} / \mathrm{vol}\right)$ & - & $10 \pm 5$ & $20 \pm 5$ & $10 \pm 5$ \\
\hline $\mathrm{Cl}_{2}\left(10^{-9} \mathrm{vol} / \mathrm{vol}\right)$ & - & $200 \pm 50$ & $200 \pm 50$ & $200 \pm 20$ \\
\hline $\mathrm{SO}_{2}\left(10^{-9} \mathrm{vol} / \mathrm{vol}\right)$ & $500 \pm 100$ & - & - & $200 \pm 20$ \\
\hline Temperature $\left({ }^{\circ} \mathrm{C}\right)$ & $25 \pm 1$ & $30 \pm 1$ & $30 \pm 1$ & $25 \pm 1$ \\
\hline R.H. $(\%)$ & $75 \pm 3$ & $70 \pm 3$ & $75 \pm 3$ & $75 \pm 3$ \\
\hline
\end{tabular}

and Telcordia, began to standardize these test methods and published corresponding documents as guidelines. The operational environments for electronic equipment in the atmosphere are divided into four classes, from least corrosive (Class I) to most corrosive (Class IV). Some examples of standard gas test methods are test methods developed by Battelle Labs, IBM, EIA-364-TP65A, Telcordia GR-63-CORE, and IEC 60068-2-60 Part 2. For the latter mentioned test method, the testing conditions are given in Table 19.1.

There is strong need to review existing mixed gas test specifications to determine their relevancy for silver-based corrosion mechanisms in relation to LED applications, specifically in a reducing sulfur environment. Understanding the relevancy of the test specifications and the potential need for modification requires a review of conditions in the field and an understanding of how the physics of the corrosion process changes with variation in these parameters.

Future versions of silver-oriented gas testing may wish to eliminate $\mathrm{SO}_{2}$ gases and increase $\mathrm{H}_{2} \mathrm{~S}$ gas concentrations to potential maximum levels encountered in heavy traffic or industry-specific harsh environments. Single flowing gas at a welldefined concentration of $\mathrm{H}_{2} \mathrm{~S}$, temperature, and relative humidity is the most common way to determine the corrosion sensitivity for low- and mid-power LED packages. Qualification tests, like IEC 62861, typically refer to the standard corrosion test method IEC 60068-2-43. Its derative standard JIS C 60068-2-43 (former JIS C 0092) differs from the IEC 60068-2-43 standard by describing an additional accelerated test condition at $40{ }^{\circ} \mathrm{C}$ at a relative humidity of $80 \%$. Standard test method IEC 60068-2-42 is less favorable as gas test for LED packages since this test method does not include exposure to $\mathrm{H}_{2} \mathrm{~S}$ and for the additional reason that tests in which MP LEDs are exposed to $\mathrm{SO}_{2}$ showed that the luminous flux is not influenced by exposure of this gas at concentration levels up to $25 \mathrm{ppm}$ (Table 19.2).

Eventually salt mist tests according to IEC 60068-2-11 or IEC 60068-2-52 are proposed as an accelerated laboratory corrosion test simulating the effects of seacoast atmosphere on devices and package elements. Apart from electrochemical corrosive effects in metallic materials, these tests may be used to indicate deterioration of some nonmetallic materials by assimilation of salts. 
Table 19.2 Single flowing gas test conditions of different standard corrosion test methods

\begin{tabular}{l|l|l|ll}
\hline Parameter & IEC 60068-2-42 & IEC 60068-2-43 & \multicolumn{2}{l}{ JIS C 60068-2-43 } \\
\hline $\mathrm{H}_{2} \mathrm{~S}\left(10^{-6} \mathrm{vol} / \mathrm{vol}\right)$ & - & $10-15$ & $10-15$ & \\
\hline $\mathrm{SO}_{2}\left(10^{-6} \mathrm{vol} / \mathrm{vol}\right)$ & $25 \pm 2$ & - & - & \\
\hline Temperature $\left({ }^{\circ} \mathrm{C}\right)$ & $25 \pm 2$ & $25 \pm 2$ & $25 \pm 2$ & $40 \pm 2$ \\
\hline R.H. $(\%)$ & $75 \pm 5$ & $75 \pm 5$ & $75 \pm 5$ & $80 \pm 5$ \\
\hline Duration (days) & $4,10,21$ & $4,10,21$ & $4,10,21$ & \\
\hline
\end{tabular}

\subsubsection{Accelerated Test Methods}

Large efforts have been made to develop accelerated corrosion tests for the purpose of product qualification. As a result of this work, a broad spectrum of methods now exists of which some are also available as international standards, as mentioned above. However, some of those tests are intended only for checking the comparative quality of a metallic material with or without corrosion protection, while others may even be useful for predicting or estimating the long-term performance of a product with metallic materials when exposed to corrosive stress representing in-service conditions. Corrosion effects may appear at air volume fractions of pollutants less than $10^{-9}$. The conduct of air pollutant corrosion tests, therefore, requires special test equipment.

For qualification of new materials and products with respect to corrosion resistance, accelerated corrosion tests generally need to be adapted during product design work. The higher the degree of acceleration of a corrosion test, the more favorable the accelerated corrosion test will be in keeping the required testing time short. On the other hand, a too large acceleration of the corrosion process may give rise to deviations from the naturally occurring corrosion processes. This makes clear the main problem in designing meaningful accelerated corrosion tests for product qualification. Identifying the most relevant method for testing the corrosion sensitivity of LED-based lighting solutions requires knowledge that usually goes beyond what you can get from a single standard.

In general, any accelerated model needs to be validated with test and real field data. For corrosion lifetime modeling, one should be very careful to assume a certain chemical reaction or physical diffusion process. Examining products from the field and comparing the corrosion rate with testing data should be done only in case the similarity of the failure mechanisms is proven. By closely studying the appearance of the surface of the corroded silver layer by means of SEM, one could verify the consistency of the layer structure and hence confirm or suspect similarity. The figure below presents micrographs of the silver-plated lead frame of mechanically de-capped LED packages. The left picture shows the corroded structure of a product after a corrosion qualification test, while at the right picture, the corroded mirror surface of a product from the field is presented. Here, the difference in structure of the corroded surfaces is unmistakable in which similarity of the failure mechanism should be questioned (Fig. 19.12). 

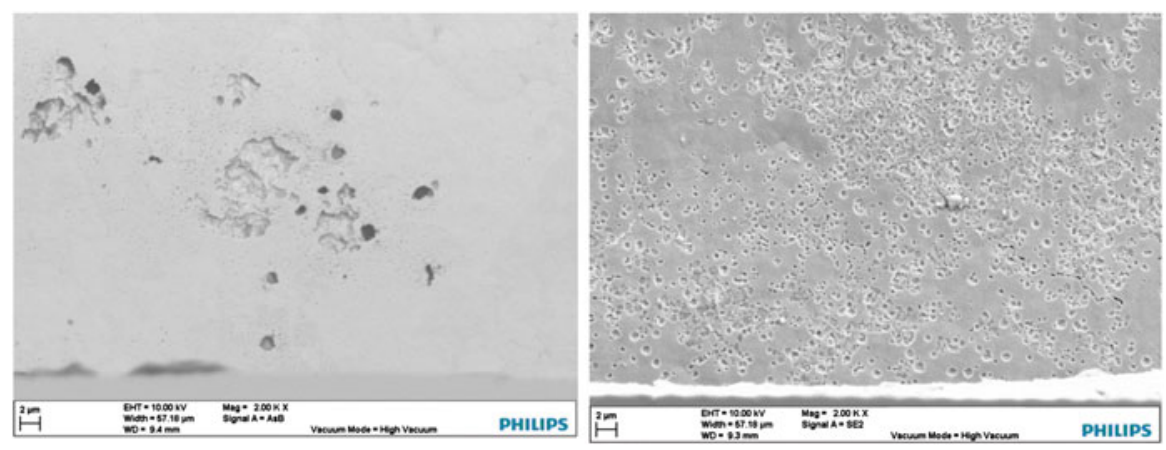

Fig. 19.12 SEM electron micrographs of chemically de-capped packages. Note the difference in appearance of the corroded mirror surfaces

In order to be able to conduct corrosion tests with a wide variety of concentrations and (combination of) types of sulfurous gasses, halogens, VOCs, or other gasses, LED manufacturers often develop nonstandard and specific testing methods for reasons of lifetime prediction and process optimization. By using power supplies and timers, also operational tests can be conducted and the influence of operational mode to corrosion sensitivity examined.

\subsection{Test Results}

Corrosion tests have been conducted to gain more insight in the sensitivity for corrosion of typical low-power and mid-power LED packages. At predefined time intervals, the product performance has been measured to be able to study timedependent product changes. In this paragraph results of corrosion tests are summarized.

\subsubsection{Sulfur Testing}

Sulfur hydrogen $\left(\mathrm{H}_{2} \mathrm{~S}\right)$ is the main contributor for silver tarnish from sulfurcontaining gasses. Below the test results are shown of several MP LED packages during a single gas test according to IEC 60068-2-43 with a volume concentration of approximately $15 \mathrm{ppm}$ of $\mathrm{H}_{2} \mathrm{~S}$ in which the differences in corrosion sensitivity is obvious (Fig. 19.13).

From the test results, it has been found that the lumen maintenance can be best described by means of a time exponential curve fit function

$$
\frac{\mathrm{dL}}{\mathrm{dt}}=-\lambda \cdot L
$$




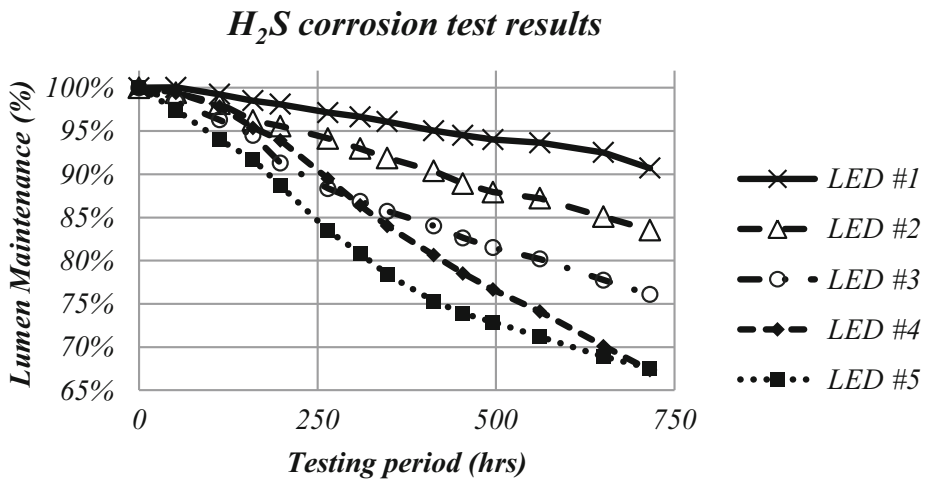

Fig. 19.13 Normalized lumen maintenance of five different LED packages during a non-operational single gas test at $15 \mathrm{ppm}_{2} \mathrm{~S}$ according to IEC 60068-2-43

where $L$ is the normalized lumen output, $t$ time, and $\lambda$ (lambda) the exponential decay constant. The solution to this equation is

$$
L(t)=B \cdot e^{-\alpha t}
$$

Here $L(t)$ is the lumen output at time $t, B$ is the initial lumen output, i.e., the lumen output at time $t=0$, and $\alpha$ represents the decay constant.

To gain insight into the influence of the concentration of a corrosive gas to the level of silver tarnish, several additional corrosive gas tests have been conducted at different concentration levels. For every LED package and at each concentration level, the emission spectrum is being measured and lumen maintenance and color consistency calculated. This provides important information about the acceleration factor of a specific corrosion test to the conditions in which the LED package is being exposed in its application. In the figure below, the projected average lifetime L70 is shown at several stress levels of $\mathrm{H}_{2} \mathrm{~S}$ for a group of MP LED packages with different levels of corrosion sensitivity. Two outliers are visible representing a package containing an Ag-protective layer (Fig. 19.14).

Next to the concentration level of the corrosive gas, also the ambient temperature and the relative humidity influence the corrosion rate. It has been found that their relationship can be drawn by Peck's and Arrhenius' equation $[17,18]$, respectively.

Finally the package integrity for corrosion of LED packages is influenced by long-term storage or exposure to thermal shock or high humidity in which even the best virgin LED packages lose their robustness against corrosion. Hence this may be a concern for either products requesting long lifetime specifications or lighting applications in harsh environments.

High-power LED packages are less sensitive for $\mathrm{H}_{2} \mathrm{~S}$ exposure since the silver plating in the EPI is protected by a passivation layer during the wafer process. Corrosion tests on HP LEDs according to IEC 60068-2-43 showed negligible lumen depreciation levels after 21 days of exposure. However, when silver plating in HP LEDs is applied to increase internal reflectivity and hence optical efficacy, these 


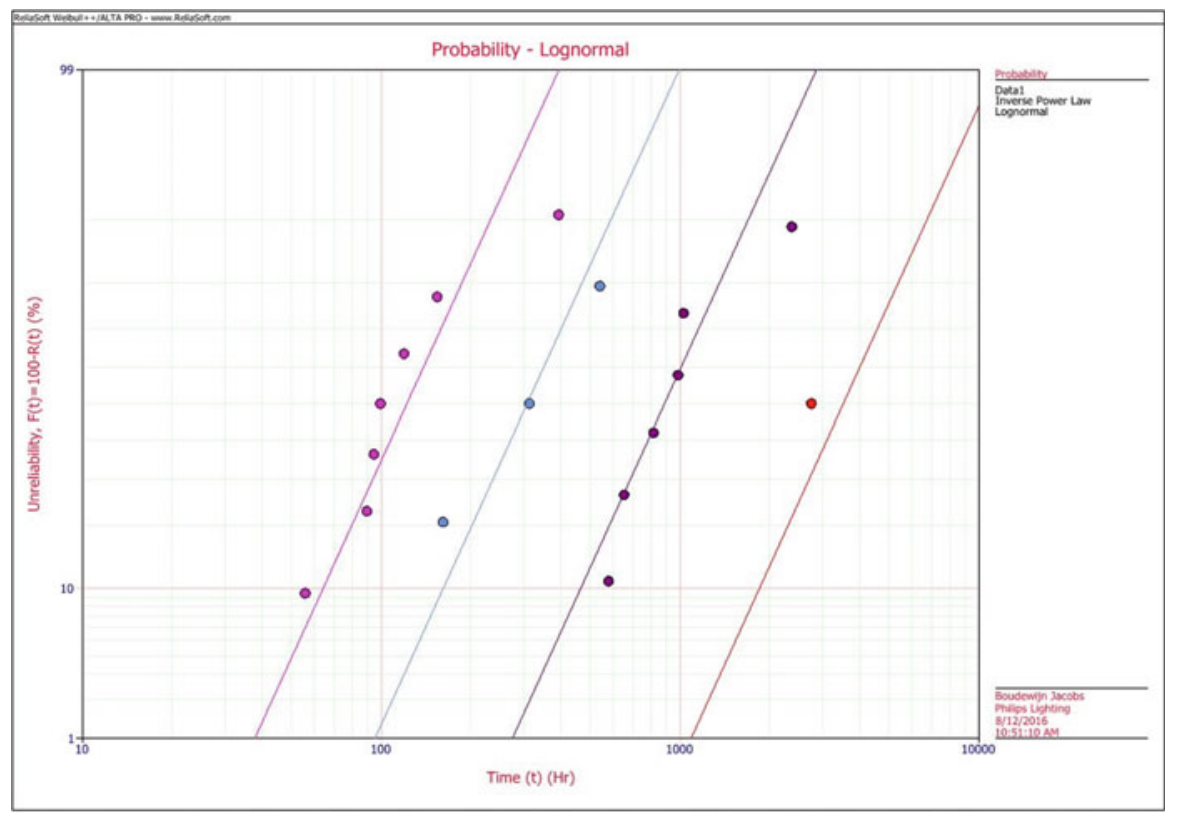

Fig. 19.14 Lifetime of typical MP LED packages at different concentrations of $\mathrm{H}_{2} \mathrm{~S}$ in air. The dots represent the probability of failure toward L70 at a certain time and concentration. $\mathrm{H}_{2} \mathrm{~S}$ concentration increases from right (red dot) to left (purple dot)

layers remain sensitive to corrosion as can be seen from the figure below. As stated earlier in this chapter, corrosion of the silver layer causes lumen maintenance issues and reduced adhesion of the wire bond attached to the corrosive surface potentially leading to high-ohmic or open electrical contacts. An example of a HP LEDs in which the silver layer has been corroded by $\mathrm{H}_{2} \mathrm{~S}$ is shown below (Fig. 19.15).

\subsubsection{Testing with Halogen Gasses}

Besides executing single gas exposure tests, also mixed gas test according to IEC 60068-2-60 is often used as qualification tests for new packages. The halogens or halogen elements are a group in the periodic table consisting of four chemically related elements: fluorine $(\mathrm{F})$, chlorine $(\mathrm{Cl})$, bromide $(\mathrm{Br})$, and iodine (I). Binary tests may be useful to determine any cross talk or acceleration effect of corrosive gasses.

\subsubsection{Testing with VOCs}

LED manufacturers of high-power LEDs clearly mention the effects of exposure to chemically incompatible volatile organic compounds in their data sheet or 

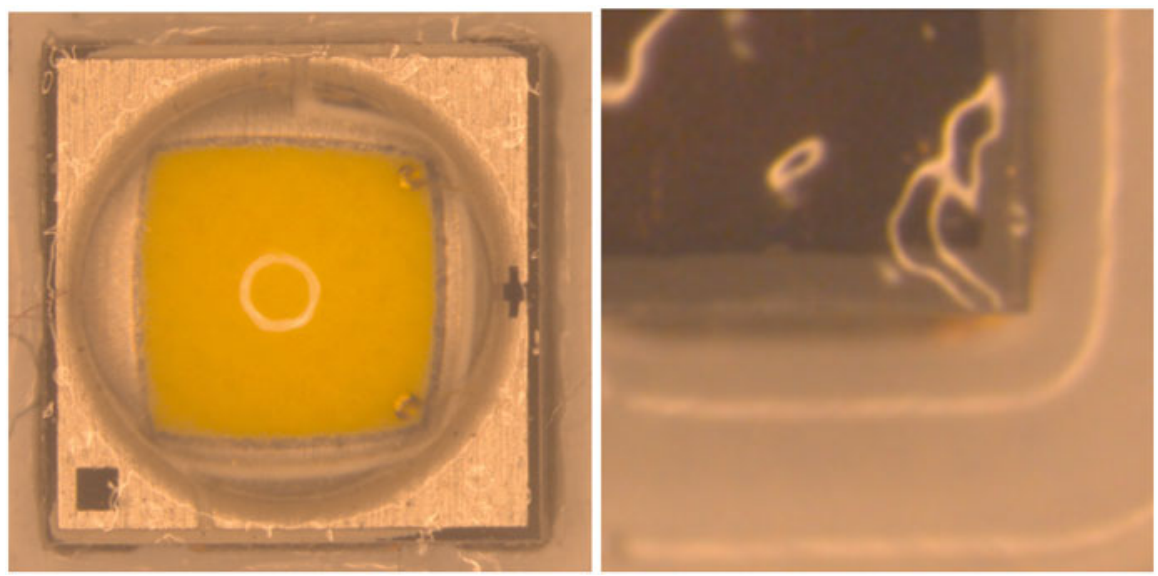

Fig. 19.15 An example of a HP LED package in which the silver-coated reflective layer has been corroded by $\mathrm{H}_{2} \mathrm{~S}$ (left picture = virgin, right picture = after corrosion testing)

separately published application notes concerning product packaging considerations and provide a list of commonly used chemicals that should be avoided as they may react with the silicone material to avoid discoloration and surface damage $[15,19-21]$. For low- and mid-power LED packages, the effect of exposure to volatile organic compounds to the lifetime is however not widely explored. To investigate if specific commonly used organic compounds give rise to "darkening" of a MP LED package, several exposure tests have been conducted.

Below the results on maintenance tests of four different types of mid-power LEDs are shown after $100 \mathrm{~h}$ and $250 \mathrm{~h}$ of operating and nonoperational exposure testing to a typical VOC class.

From the figure below, we can see that for the selected class of VOC the lumen maintenance of LED type \#4 does no seem to be affected whilst LED type 3 seems most vulnerable of all tested LED types, but in operational mode only (Fig. 19.16). On samples D16 and D17 the area underneath the LED die is clearly blackened suspecting interaction with the die attach glue. Hence it is believed that the generation of blue light seems necessary to trigger oxidation.

\subsection{Harmful Chemicals}

A list of classes of chemicals, often found in electronics and construction materials for luminaires that should be avoided, is provided in the table below. Although some LED manufacturers provide exhaustive lists of harmful chemical [19-21], please note that it is impossible to determine all chemicals that may affect LED performance. 


\section{LED type \#1 LED type \#2 LED type \#3 $\quad$ LED type \#4}

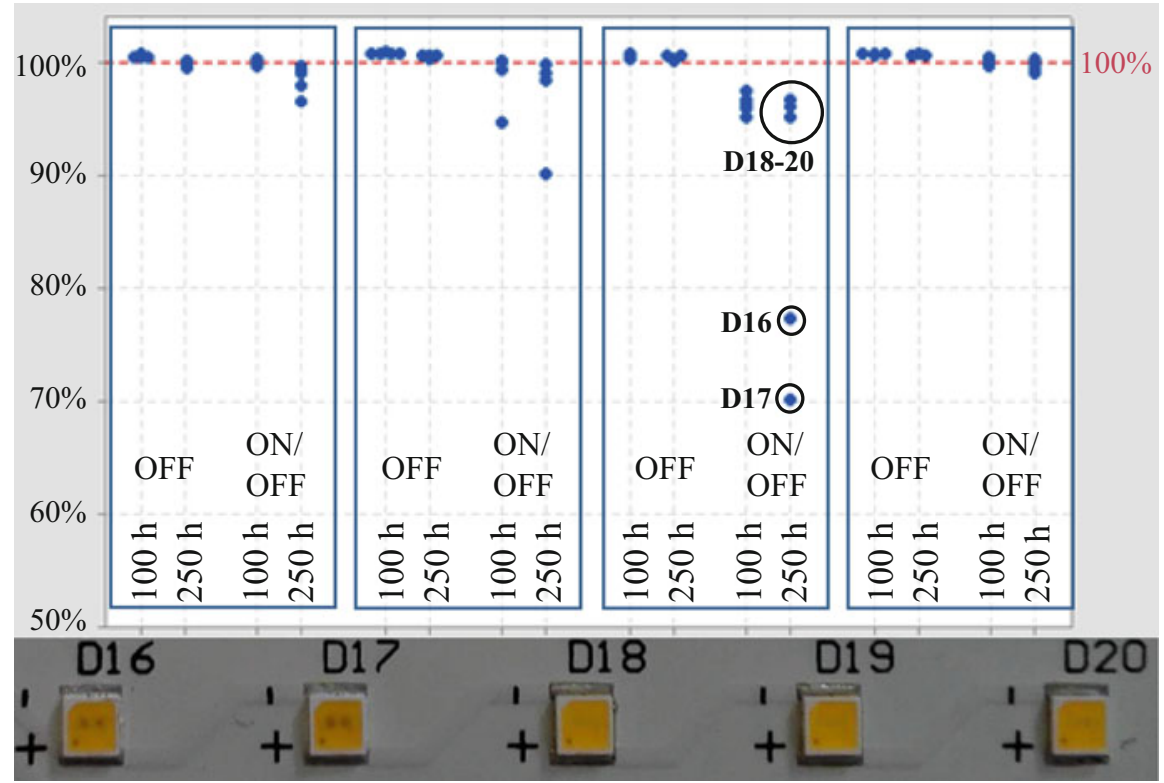

Fig. 19.16 Normalized lumen maintenance results during VOC exposure tests on several MP LED packages

Table 19.3 List of classes of chemicals hazardous for LED-based products [19-21]

\begin{tabular}{l|l}
\hline Class & Typical hazardous compounds \\
\hline Acids & $\begin{array}{l}\text { Hydrochloric acid, nitric acid, phosphoric acid, sulfuric } \\
\text { acid, phthalic acid }\end{array}$ \\
\hline Hydroxides & Amines, potassium hydroxide, sodium hydroxide \\
\hline Low molecular mass organics & $\begin{array}{l}\text { Acetate, acetone, acrylate, aldehydes, dienes, ether, ethyl } \\
\text { acetate, formaldehyde }\end{array}$ \\
\hline Organic and aromatic solvents & $\begin{array}{l}\text { Benzene, benzotriazole, butyl acetate, chloroform, } \\
\text { chloromethane, glycol, ketones such as MEK, MIBK, tolu- } \\
\text { ene and xylene }\end{array}$ \\
\hline Petroleum oils & Cleaning or oil-assisted cleaning oil, diesel, petroleum \\
\hline Phthalic acid-based plasticizers & DOP, DEP, DNHP, DIP \\
\hline $\begin{array}{l}\text { Sulfur- and halogen-containing } \\
\text { chemical compounds }\end{array}$ & $\begin{array}{l}\mathrm{H}_{2} \mathrm{~S} \text { and thiol-containing organic compounds, halogens like } \\
\text { chlorine, fluor, bromide and iodine }\end{array}$ \\
\hline
\end{tabular}

In addition to chemical contamination due to outgassing, consideration must also be given to the environment in which the final product will be installed and operated. All possible environmental conditions therefore have to be taken into account when designing a LED luminaire (Table 19.3). 


\subsection{Conclusion}

In this chapter, the sensitivity for corrosion of LED packages been discussed. Different sources for corrosion can be distinguished in which examples of both intrinsic and extrinsic corrosion are presented. The sensitivity for corrosion of a LED package mainly depends upon the package integrity and the use of corrosive materials inside the package. Possible passages for corrosive gases have been illustrated as well as the application of corrosion-sensitive materials inside the LED package. By design, LED packages become more sensitive for silver tarnish in case of a high probability of emitted photons hitting the lead frame before leaving the package.

From the standard single and mixed flowing gas test methods, the accelerated test conditions as mentioned in IEC 60068-2-43 and JIS C 60068-2-43 seem most appropriate to determine the sensitivity for corrosion for a low- and mid-power LED package. However, investigation of the morphology of the corroded surface may be necessary to verify consistency in the crystal formation to be able to reproduce the failure mechanism similar to the actual environment. Although HP LEDs are less sensitive for corrosion, an example of a high-power LED package bearing silver corrosion is shown.

From gas exposure tests, the relationship between the concentration of $\mathrm{H}_{2} \mathrm{~S}$ and the lifetime of the LED package has been shown. VOC tests showed that specific mid-power LED packages are more vulnerable for exposure to organic compounds than other and that in some cases the generation of blue light is necessary to trigger oxidation.

As a general guideline, a list of classes of chemicals is mentioned that should be avoided as they may affect LED performance.

\section{References}

1. M.H. Chang, D. Das, P.V. Varde, M. Pecht, Light emitting diodes reliability review. Microelectron. Reliab. 52, 762-782 (2012)

2. S.D. Shepherd, K.C. Mills, R. Yaga, C. Johnson, J.L. Davis, in Proceedings of the SPIE 9190. New understandings of failure modes in SSL luminaires (2014)

3. R. Tuttle, LED System Lifetime and Reliability: LED Components, presented at Strategies in Light, Las Vegas 2015

4. JEP122F, Failure Mechanisms and Models for Semiconductor Devices, JEDEC Solid State Technology Association, South Arlington 2010

5. S. Watzke, P. Altieri-Weimar, in 2014 15th International Conference on Thermal, Mechanical, and Multi-physics Simulation and Experiments in Microelectronics and Microsystems. Degradation of silicone in white LEDs during device operation: a finite element approach to product reliability prediction (IEEE EuroSimE, Ghent, 2014)

6. M. Buffolo, C. De Santi, M. Meneghini, D. Rigon, G. Meneghesso, E. Zanoni, Long-term degradation mechanisms of mid-power LEDs for lighting applications. Microelectron. Reliab. 55, 1754-1758 (2015) 
7. W.D. van Driel, X.J. Fan, Solid State Lighting Reliability: Components to Systems (Springer, 2012), 617 pages, ISBN 978-1-4614-3066-7

8. J.L. Davis, K. Mills, M. Lamvik, R. Yaga, S.D. Shepherd, J. Bittle, N. Baldasaro, E. Solano, G. Bobashev, C. Johnson, A. Evans, in Proceedings of the 2014 15th International Conference on Thermal, Mechanical, and Multi-physics Simulation and Experiments in Microelectronics and Microsystems. System reliability for LED-based products (IEEE EuroSimE, Ghent, 2014)

9. J.L. Davis, Solid-state lighting luminaire reliability, presentation at Delft University, Delft, 2014

10. J.L. Davis, Color shift in LEDs and SSL luminaires, presentation at the 2014 DOE Solid-State Lighting Manufacturing R\&D Workshop, San Diego, 2014

11. M.Y. Mehr, W.D. van Driel, G.Q. Zhang, Accelerated life time testing and optical degradation of remote phosphor plates. Microelectron. Reliab. 54, 1544 (2014)

12. G. Lu, M. Yazdan Mehr, W.D. van Driel, X. Fan, J. Fan, K.M.B. Jansen, G.Q. Zhang, Color shift investigations for LED secondary optical designs- comparison between BPA-PC and PMMA. Opt. Mater. 45, 37-41 (2015)

13. Huang J, Golubović DS, Koh S, Yang D, Li X, Fan X, Zhang GQ, Rapid degradation of mid-power white-light LEDs in saturated moisture conditions. IEEE Trans. Device Mater. Reliab. 99 (2015)

14. J. Huang, D.S. Golubović, S. Koh, D. Yang, X. Li, X. Fan, G.Q. Zhang, Degradation modeling of mid-power white-light LEDs by using wiener process. Opt. Express 23, A966-A978 (2015)

15. Philips Lumileds, Luxeon Rebel Platform Assembly and Handling Information, Application Brief 20150330 (n.d.)

16. http://www.calce.umd.edu/TSFA/MFG.pdf, Mixed Flowing Gas Testing Introduction and CALCE MFG Capability

17. F. Jensen, Electronic Component Reliability (Wiley, 1995), ISBN 0-471-95296-6

18. W. B. Nelson, Accelerated Testing: Statistical Models, Test Plans, and Data Analysis (Wiley Series in Probability and Statistics) (1990), ISBN 0-471-52277-5

19. Osram, Preventing LED Failures caused by corrosive Materials, Application Note (2013), http://www.osram-os.com/Graphics/XPic1/00088375_0.pdf/Preventing

20. Samsung Electronics LED Business, Chemical guide of LED component (2013), http://www. samsung.com/global/business/businessimages/ led/file/product/lighting/201408/Application Note_Chemical_Guide_for_LED_Component_Rev.1.3.pdf

21. Cree, Cree XLamp LEDs Chemical Compatibility, Support document CLD-AP63 rev 0A (2012), http://www.cree.com/led-components/media/documents/XLamp_Chemical_Comp. pdf 